\title{
DIAGNÓSTICO DA ARBORIZAÇÃO DAS VIAS PÚBLICAS DO MUNICÍPIO \\ DE SETE DE SETEMBRO - RS
}

\author{
Elizete Patrícia Coletto ${ }^{1}$, Nilvane G. Müller ${ }^{2}$, Silvia Scherer Wolski ${ }^{3}$
}

(recebido em 07.12.2007 e aceito para publicação em 20.06.2008)

\begin{abstract}
RESUMO
O objetivo deste trabalho foi diagnosticar a arborização das vias públicas do Município de Sete de Setembro, RS. Adicionalmente, o trabalho se propõe a identificar problemas e apontar sugestões que contribuam para a definição futura de diretrizes de planejamento da arborização. A metodologia empregada consistiu, basicamente, no levantamento de todos os indivíduos vegetais existentes nas vias públicas do município. Para tanto, foram percorridas todas as ruas da cidade, preenchendo-se uma planilha de levantamento com informações referente às ruas, aos passeios e mais detalhadamente sobre cada exemplar vegetal. A coleta de dados compreendeu o período de dezembro de 2005 a fevereiro de 2006, verificando-se a ocorrência de 773 indivíduos, pertencentes a 24 famílias e 60 espécies. As espécies encontradas com maior freqüência foram Thuja plicata (Tuia), Bauhinia variegata (Pata-de-vaca), Murraya paniculata (Falsa murta), Lagerstroemia indica (Extremosa), Ligustrum spp (Ligustro), Cinnamomum spp (Canelinha), representando 70\% da arborização do município.
\end{abstract}

Palavras-chave: arborização urbana - meio ambiente urbano - planejamento urbano.

\footnotetext{
${ }^{1}$ Bióloga, Acadêmica do Curso de Especialização em Ciências Ambientais da Universidade Regional Integrada do Alto Uruguai e das Missões - URI, campus de Santo Ângelo, RS. E-mail: patriciacoletto@gmail.com.

${ }^{2}$ Bióloga, Professora Doutora da Universidade Regional Integrada do Alto Uruguai e das Missões URI, campus de Santo Ângelo, RS. E-mail: nil@urisan.tche.br.

${ }_{3}^{3}$ Engenheira Florestal, M.Sc., Secretaria da Agricultura, Pecuária, Pesca e Agronegócio do Estado do RS. E-mail: srscherer@sol.psi.br.
} 


\title{
DIAGNOSE THE PUBLIC WAYS ARBORIZATION OF THE CITY OF \\ SETE DE SETEMBRO - RS
}

\begin{abstract}
The aim of the present work was to diagnose the public ways arborization in the city of Sete de Setembro - RS. Additionally, the work considers to identify problems and to point suggestions that contribute for the future planning of the arborization. The adopted methodology consisted, basically, on the gathering of all plants existing in the public ways of the city. In order to achieve this, all the city streets were roamed about and the information about streets, sidewalks and more detailed plant descriptions was registered on a spreadsheet. Data collection took place between December 2005 and February 2006 verifying the occurrence of 773 plants belonging to 24 families and 60 species. The species found more often were Thuja plicata (Tuia), Bauhinia variegata (Pata-de-vaca), Murraya paniculata (Falsa Murta), Lagerstroemia indica (Extremosa), Ligustrum spp (Ligustro), Cinnamomum spp (Canelinha), representing $70 \%$ of the city arborization.
\end{abstract}

Key-words: urban arborization - urban environment - urban projection. 


\section{INTRODUÇÃO}

As ruas formam o tecido urbano da cidade, identificando os lugares e as pessoas. Sendo estas corretamente arborizadas, formam uma paisagem belíssima e indispensável à vida humana, assumindo um importante papel no município.

A árvore é a forma vegetal mais característica na paisagem urbana, a qual, ao longo da história, tem se incorporado em estreita relação com a arquitetura das cidades. A arborização urbana contribui para obter um ambiente urbano agradável e tem influência decisiva na qualidade de vida nas cidades e, portanto, na saúde da população. A importância da árvore, no meio urbano, ganha relevância maior, principalmente quando a concentração das habitações aumenta (MÜLLER, 1998).

A arborização urbana em vias públicas é fundamental para manutenção da qualidade de vida, proporcionando conforto aos habitantes das cidades, pois contribui com a estabilização climática, embeleza, fornece abrigo e alimento à fauna e sombra e lazer às ruas e avenidas das cidades. Contudo, quando não há planejamento desta arborização, inúmeros problemas podem ocorrer e ao invés de um elemento benéfico, a arborização passa a representar um foco de conflito nas cidades.

A história da arborização urbana no Brasil ainda é recente, porém se observa uma grande preocupação em encontrar a árvore ideal para a arborização de ruas, a qual se compatibilize às condições, quanto a aspectos estruturais, fisiológicos e ambientais, para que se assegure sucesso quanto ao plantio ao longo das vias (HOEHENE, 1944, citado por SANTOS E TEIXEIRA, 2001).

Planejar a arborização é indispensável para o desenvolvimento urbano e requer, antes de qualquer coisa, o conhecimento da situação existente, através de um inventário quali-quantitativo, assim como o conhecimento das características dos vegetais que poderão ser utilizados.

A arborização de cidades realizada de forma planejada apresenta-se como uma opção para melhoria da qualidade ambiental urbana, tendo em vista os benefícios diretos e indiretos pelas áreas verdes e árvores de ruas (DETZEL, 1992).

O município de Sete de Setembro, embora seja um município novo, já convive com conflitos na arborização de suas ruas, entre os quais a predominância de espécies exóticas, a não observação de preceitos técnicos na execução dos plantios e a ausência de manutenção da arborização.

Assim, com a finalidade de conhecer a arborização do município de Sete de Setembro e contribuir para a definição de diretrizes de planejamento da arborização, realizou-se o levantamento das espécies vegetais existentes nas vias públicas de toda a área urbana do município e a identificação dos principais problemas existentes no local. 


\section{MATERIAIS E MÉTODOS}

O estudo foi realizado no perímetro urbano do município de Sete de Setembro, município emancipado em 1995 e localizado na região noroeste do estado do Rio Grande do Sul.

O município possui uma área de $130 \mathrm{~km}^{2}$ e uma população de 2.357 habitantes, dos quais 386 residem na área urbana. Localiza-se a uma latitude de $28^{\circ} 07^{\prime} 52^{\prime \prime}$ Sul e a uma longitude de 54²7'48" Oeste. O clima é subtropical e a altitude da sede é de 273 metros (INSTITUTO BRASILEIRO DE GEOGRAFIA E ESTATÍSTICA, 2005). Com característica essencialmente agrícola, está inserido no bioma Mata Atlântica, na região fitoecológica da Floresta Estacional Decidual (RIO GRANDE DO SUL, 2008).

A metodologia empregada consistiu, basicamente, no levantamento de todos os indivíduos vegetais existentes nas vias públicas do município. A identificação das espécies ocorreu com a consulta bibliográfica em LORENZI (1998, 2000, 2001, 2004), BACKES e IRGANG $(2002,2004)$ e LONGHI (1995). O diagnóstico foi efetuado com o uso de uma planilha de levantamento de dados, coletando-se dados referentes às ruas, aos passeios e aos indivíduos vegetais existentes. Em relação às ruas e aos passeios, foram levantados os seguintes dados: nome da rua, largura, direção, lado, largura da calçada, presença ou ausência de fiação elétrica, altura aproximada da fiação e identificação de baixa ou alta tensão. Em relação aos indivíduos vegetais inventariados, foram levantados: número do imóvel em frente ao qual o exemplar estava localizado, espécie (nome vulgar), muda (sim ou não), altura em metros, circunferência à altura do peito (CAP) em centímetros, condição geral da árvore, situação da raiz em relação à calçada, afastamento predial, área livre de solo exposto (em metros quadrados); espaçamento entre árvores (em metros), distância do vegetal à parte externa do meio-fio (em centímetros), compatibilização entre o porte da árvore e o espaço disponível, potencialidade para plantio e observações.

A medição da altura das árvores foi feita com trena para os casos em que o indivíduo apresentava porte médio, ou seja, até 6 metros. Para o caso das árvores de grande porte, estimou-se a altura levando em consideração a altura da fiação elétrica nos casos em que esta estava presente. Para medir a circunferência à altura do peito (1,30 $\mathrm{m}$ do solo) foi utilizada fita métrica comum, assim como para obter a distância das árvores ao meio-fio e a área livre de solo exposto no entorno da árvore.

A coleta de dados compreendeu o período de dezembro de 2005 a fevereiro de 2006. Os dados coletados foram inseridos em um banco de dados construído no software Microsoft Access 7.0. 


\section{RESULTADOS E DISCUSSÕES}

\section{Levantamento da arborização}

Nas ruas do município de Sete de Setembro foram encontradas 773 plantas arbóreas, pertencentes a 24 famílias e 60 espécies, como mostra a tabela 01. Dentre estas, destaca-se Thuja plicata com $18,63 \%$ do total avaliado. Ainda merecem destaque as espécies Bauhinia variegata, Murraya paniculata, Lagerstroemia indica, Ligustrum spp, e Cinnamomum spp, que, juntas, respondem por quase $70 \%$ da arborização do município. 0 resultado encontrado mostrou-se próximo da recomendação técnica de GREY \& DENEKE (1978) apud MILANO (1984) de que cada espécie não atinja mais do que 10 a 15\% dos plantios. Apenas Thuja plicata supera a indicação de 15\% de plantio. Os 30\% restantes da arborização estão constituídos pelas demais 53 espécies, sendo que para 22 destas espécies foi verificada a ocorrência de apenas um indivíduo.

Das 60 espécies encontradas, 35 são exóticas à flora brasileira e 24 foram identificadas como nativas. Merece destaque a ocorrência de 11 espécies consideradas invasoras, de acordo com o INSTITUTO HÓRUS DE DESENVOLVIMENTO E CONSERVAÇÃO AMBIENTAL (2008). Destas, Murraya paniculata é a mais freqüente, com o plantio de 94 exemplares, correspondendo a 12,1\% da arborização.

Em levantamento realizado por TEIXEIRA (1999), no Conjunto Habitacional Tancredo Neves, em Santa Maria, RS, foi observado que $70,6 \%$ da arborização estavam constituídos por 14 espécies. SANTOS \& TEIXEIRA (1990), avaliando o bairro Centro do mesmo município, haviam encontrado problema similar: cinco espécies concentravam mais de 70\% da arborização. Trabalho realizado em Porto Alegre, RS, (PORTO ALEGRE, 1996) encontrou três espécies também exóticas (Ligustrum sp, Jacaranda mimosaefolia e Lagerstroemia indica) respondendo por $50 \%$ da arborização do município. Para SOUZA (1994), citado por TEIXEIRA (1999), observa-se uma uniformidade quanto ao emprego de certas espécies na arborização de cidades brasileiras, o que se pode supor ser conseqüência normal de uma cidade procurar imitar a arborização de outra. Isto resulta em um número reduzido de espécies, sempre acompanhadas dos mesmos problemas.

O número de espécies frutíferas encontradas foi significativo, com 16 espécies diferentes, que, juntas, representam $12 \%$ da composição da arborização do município. 0 uso de frutíferas nativas na arborização é recomendado sob o ponto de vista ambiental para propiciar a atração da fauna silvestre para a cidade. No levantamento, foi possível perceber que os plantios de frutíferas, em geral, correspondem a ações não planejadas, de apenas um ou dois exemplares, feitos de forma espontânea pela população com a finalidade de alimentação humana. 
Tabela 01. Relação das famílias, espécies, número de indivíduos e da freqüência dos exemplares vegetais encontrados na arborização das vias públicas do Município de Sete de

Setembro, RS. 2005.

\begin{tabular}{|c|c|c|c|c|c|}
\hline Família & Nome científico & Nome Popular & $\begin{array}{c}\text { Origem } \\
\text { (1) }\end{array}$ & $\begin{array}{l}\mathrm{N}^{\circ} \text { de } \\
\text { ind. }\end{array}$ & Freq. (\%) \\
\hline Cupressaceae & Thuja plicata & Tuia & $\mathrm{E}$ & 144 & 18.63 \\
\hline Leguminosae-caesalpinioideae & Bauhinia sp & Pata-de-vaca & $\mathrm{E}$ & 99 & 12.80 \\
\hline Rutaceae & Murraya paniculata & Falsa-murta & $\mathrm{E}$ & 94 & 12.16 \\
\hline Lythraceae & Lagerstroemia indica & Extremosa & $\mathrm{E}$ & ,76 & 9.83 \\
\hline Oleaceae & Ligustrum $s p$ & Ligustro & $E$ & 58 & 7.50 \\
\hline Lauraceae & Cinnamomum $s p$ & Falsa-canela & $\mathrm{E}$ & 46 & 5.95 \\
\hline Meliaceae & Melia azedarach & Cinamomo & $\mathrm{E}$ & 36 & 4.66 \\
\hline Cupressaceae & Chamaecyparis $s p$ & Cipreste & $\mathrm{E}$ & 18 & 2.33 \\
\hline Rosaceae & Prunus serrulatas & Cerejeira-do-japão & $\mathrm{E}$ & 18 & 2.34 \\
\hline Myrtaceae & Myrcianthes pungens & Guabijú & $\mathrm{N}$ & 16 & 2.07 \\
\hline Rutaceae & Citrus sinensis & Laranjeira & $\mathrm{E}$ & 15 & 1.94 \\
\hline Bignoniaceae & Jacaranda mimosaefolia & Jacarandá-mimoso & $E$ & 12 & 1.55 \\
\hline Rutaceae & Citrus reticulata & Bergamoteira & $\mathrm{E}$ & 9 & 1.16 \\
\hline Altingiaceae & Liquidambar styraciflua & Liquidambar & $\mathrm{E}$ & 9 & 1.16 \\
\hline Myrtaceae & Psidium sp & Araçazeiro & $\mathrm{N}$ & 8 & 1.03 \\
\hline Myrtaceae & Acca sellowiana & Goiabeira-serrana & $\mathrm{N}$ & 8 & 1.03 \\
\hline Rosaceae & Prunus persica & Pessegueiro & $\mathrm{E}$ & 7 & 0.89 \\
\hline Proteaceae & Grevillea robusta & Grevilha & $\mathrm{E}$ & 6 & 0.77 \\
\hline Myrtaceae & Eugenia uniflora & Pitangueira & $\mathrm{N}$ & 6 & 0.77 \\
\hline Aracaceae & Butia spp & Butiá & $\mathrm{N}$ & 6 & 0.77 \\
\hline Anacardiaceae & Mangifera indica & Mangueira & $\mathrm{E}$ & 5 & 0.65 \\
\hline Leguminosae-papilionoideae & Ateleia glazioveana & Timbó & $\mathrm{N}$ & 5 & 0.65 \\
\hline Leguminosae-caesalpinioideae & Cassia fistula & Cássia-imperial & $\mathrm{E}$ & 5 & 0.65 \\
\hline Bignoniaceae & Tabebuia avallanedae & Ipê-roxo & $\mathrm{N}$ & 5 & 0.65 \\
\hline \multirow[t]{2}{*}{ Malvaceae } & Hibiscus rosa-sinensis & Hibisco & E & 4 & 0.52 \\
\hline & Não identificada & Não identificada & - & 4 & 0.52 \\
\hline Bignoniaceae & Jacaranda micrantha & Caroba & $\mathrm{N}$ & 4 & 0.52 \\
\hline Lauraceae & Nectandra membranacea & Canela & $\mathrm{N}$ & 4 & 0.52 \\
\hline Leguminosae-caesalpinioideae & Caesalpinia peltophoroides & Sibipiruna & $\mathrm{N}$ & 3 & 0.39 \\
\hline Aracaceae & Syagrus romanzoffiana & Jerivá & $\mathrm{N}$ & 3 & 0.39 \\
\hline Rosaceae & Eriobotrya japonica & Nêspera & $\mathrm{E}$ & 3 & 0.39 \\
\hline Leguminosae-caesalpinioideae & Senna bicapsularis & Fedegoso & $\mathrm{N}$ & 3 & 0.39 \\
\hline Rutaceae & Citrus limonum & Limoeiro & $E$ & 2 & 0.26 \\
\hline Anacardiaceae & Schinus terebinthifolius & Aroeira-vermelha & $\mathrm{N}$ & 2 & 0.26 \\
\hline Moraceae & Morus nigra & Amora-preta & $\mathrm{E}$ & 2 & 0.26 \\
\hline Solanaceae & Brunfelsia uniflora & Primavera & $\mathrm{N}$ & 2 & 0.26 \\
\hline Leguminosae-caesalpinioideae & Senna macranthera & Manduirana & $\mathrm{N}$ & 2 & 0.26 \\
\hline Rhamnaceae & Hovenia dulcis & Uva-do-japão & $\mathrm{E}$ & 2 & 0.26 \\
\hline Myrtaceae & Psidium guajava & Goiabeira & $\mathrm{E}$ & 1 & 0.13 \\
\hline Punicaceae & Punica granatum & Romanzeira & $\mathrm{E}$ & 1 & 0.13 \\
\hline Pinaceae & Pinus taeda & Pinus & $\mathrm{E}$ & 1 & 0.13 \\
\hline Moraceae & Ficus benjamina & Ficus-benjamina & $\mathrm{E}$ & 1 & 0.13 \\
\hline Leguminosae-papilionoideae & Tipuana tipu & Tipuana & $\mathrm{E}$ & 1 & 0.13 \\
\hline Myrtaceae & Callistemon viminalis & Escova-de-garrafa-pendente & $\mathrm{E}$ & 1 & 0.13 \\
\hline Sapindaceae & Cupania vernalis & Camboatá & $\mathrm{N}$ & 1 & 0.13 \\
\hline Leguminosae-caesalpinioideae & Delonix regia & Flamboiã & $E$ & 1 & 0.13 \\
\hline Myrtaceae & Eugenia involucrata & Cerejeira & $\mathrm{N}$ & 1 & 0.13 \\
\hline Leguminosae-caesalpinioideae & Caesalpinia sappan & Falso-pau-brasil & $\mathrm{E}$ & 1 & 0.13 \\
\hline Anacardiaceae & Schinus molle & Aroeira-salsa & $\mathrm{N}$ & 1 & 0.13 \\
\hline Proteaceae & Grevillea bankssii & Grevilha-anã & $\mathrm{E}$ & 1 & 0.13 \\
\hline Araucareaceae & Araucaria angustifolia & Pinheiro-brasileiro & $\mathrm{N}$ & 1 & 0.13 \\
\hline Sapindaceae & Allophyllus edulis & Chal-chal & $\mathrm{N}$ & 1 & 0.13 \\
\hline Leguminosae-mimosoideae & Parapiptadenia rigida & Angico-vermelho & $\mathrm{N}$ & 1 & 0.13 \\
\hline Meliaceae & Cedrela fissilis & Cedro & $\mathrm{N}$ & 1 & 0.13 \\
\hline Platanaceae & Platanus acerifolia & Plátano & $\mathrm{E}$ & 1 & 0.13 \\
\hline Bignoniaceae & Tabebuia chrysotricha & Ipê-amarelo & $\mathrm{N}$ & 1 & 0.13 \\
\hline Myrtaceae & Myrciaria cauliflora & Jabuticabeira & $\mathrm{N}$ & 1 & 0.13 \\
\hline Myrtaceae & Eucalyptus ficifolia & Eucalipto-vermelho & $\mathrm{E}$ & 1 & 0.13 \\
\hline Araucariaceae & Araucaria heterophylla & Araucária & $\mathrm{E}$ & 1 & 0.13 \\
\hline Salicaceae & Populus alba & Álamo-prateado & $\mathrm{E}$ & 1 & 0.13 \\
\hline
\end{tabular}

(1) $E=$ exótica

$\mathrm{N}=$ Nativa 
Em relação à distribuição de alturas, 531 dos indivíduos avaliados apresentaram altura igual ou inferior a 3 metros, sendo que, destes, $336(43,4 \%)$ foram classificados como mudas, valor semelhante ao verificado no levantamento realizado por Teixeira (1999), que encontrou 40,7\% das árvores avaliadas com porte de muda. Entre as espécies recém plantadas, destaca-se a Murraya paniculata com 27,9\% dos exemplares jovens encontrados, o que demonstra que há um trabalho de arborização sendo feito atualmente que, no entanto, não vem privilegiando a diversificação de espécies e tampouco o plantio de espécies nativas. A preferência de uso de espécies nativas na arborização é uma recomendação nem sempre seguida pelos municípios e recentemente reforçada na Carta de Vitória $^{4}$ (CONGRESSO BRASILEIRO DE ARBORIZAÇÃO URBANA, 2007). Aproximadamente 206 indivíduos apresentaram altura entre 3 metros e 6 metros e com altura entre 6 metros e 9 metros foram encontradas apenas 35 árvores. A pouca idade do município - apenas 10 anos de emancipação político-administrativa - é um aspecto que explica o pequeno porte dos indivíduos encontrados. A realização periódica de podas nas árvores plantadas sob rede de fiação elétrica, de forma a mantê-las com um porte inferior à altura da rede, também ajuda a explicar esta situação.

A circunferência à altura do peito (CAP) é outro parâmetro que possibilita uma idéia do porte dos indivíduos que compõem a arborização do município. O CAP mínimo encontrado foi de apenas dois $\mathrm{cm}$, o máximo foi de $263 \mathrm{~cm}$ e a média avaliada foi de $58,7 \mathrm{~cm}$ (diâmetro à altura do peito - DAP - de aproximadamente $19 \mathrm{~cm}$ ).

Em relação à condição geral da árvore, os indivíduos avaliados foram classificados em quatro categorias de acordo com sua condição fitossanitária e necessidade de trabalhos de correção ou recuperação. A grande maioria - 668 indivíduos ou $86,4 \%$ - foi classificada como árvore boa, vigorosa, que não requer trabalhos de correção. Esta situação é superior à avaliada por MILANO (1988) em Maringá - PR, onde 51,9\% das árvores foram classificadas como boas e em Curitiba (MILANO, 1984), em que o percentual de árvores boas foi de 37,8\%. Outros 83 indivíduos (10,74\%) apresentaram-se como satisfatórios, de vigor médio, necessitando de tratos culturais para recuperação. Em estado ruim ou em declínio, apresentando severos danos e requerendo trabalhos de correção, foram verificados 22 indivíduos (2,84\%) e apenas três exemplares mortos.

Outro aspecto avaliado nos levantamentos diz respeito ao espaço livre disponível no entorno das árvores. Em grande parte das situações, este parâmetro não pôde ser obtido, pois os passeios não possuíam revestimento, estando cobertos por grama, pedras de calçamento ou mesmo solo exposto. Nos casos avaliados, o resultado observado apresentou-se bastante aquém da recomendação preconizada pela literatura especializada

\footnotetext{
${ }^{4}$ Carta elaborada na assembléia geral constituída pelos participantes do XI Congresso Brasileiro de Arborização Urbana, realizado em Vitória, ES.
} 
que indica uma área livre de um metro quadrado como mínimo a ser destinado para um bom desenvolvimento das árvores plantadas em vias públicas (GONÇALVES, 1997). Somente em três casos o espaço disponibilizado para a planta ultrapassou um metro quadrado. A área livre mínima encontrada foi de 0,04 $\mathrm{m}^{2}$, a máxima foi de $1,73 \mathrm{~m}^{2}$ e a área média observada foi de $0,27 \mathrm{~m}^{2}$. Em Campos do Jordão, SP, ANDRADE (2002) encontrou 64,8\% das árvores avaliadas com área livre superior a um metro quadrado.

$\mathrm{Na}$ cidade, como um todo, foi observada a predominância de calçadas sem danos causados pelas raízes das árvores, aspecto este condicionado pelo grande número de mudas e árvores jovens. Foi constatada a ocorrência de 725 indivíduos com raiz totalmente subterrânea, 13 indivíduos com raiz de forma superficial apenas na área de crescimento da árvore e 35 indivíduos com raiz de forma superficial, ultrapassando a área de crescimento da árvore, provocando rachadura nas calçadas. Em Piracicaba, SP (LIMA, 1993 citado por ANDRADE, 2002), 29,3\% das raízes estavam evidentes e em Curitiba (MILANO, 1884) apenas $3 \%$.

O espaçamento entre árvores também foi avaliado, tendo sido verificado um espaçamento mínimo de cinco centímetros, médio de 6,87 metros e o máximo de 127 metros. Foi possível perceber que muitos plantios realizados pela população não obedecem ao espaçamento mínimo recomendado para cada espécie em função de sua dimensão quando adulta (diâmetro de copa).

O recuo das construções em relação ao início do passeio foi avaliado com o propósito de verificar a compatibilidade das espécies plantadas com o espaço disponível, principalmente levando-se em consideração que espécies de porte médio ou grande necessitam de mais espaço físico para seu pleno desenvolvimento. Foi verificado que cerca de $60 \%$ dos exemplares avaliados encontravam-se plantados em frente a construções com recuo, ou seja, construções com afastamento em relação ao passeio público. Outros $9 \%$ estavam localizados em frente a edificações com recuo insuficiente e $7 \%$ do total avaliado localizavam-se em frente a edificações sem recuo. O restante encontrava-se em frente a terrenos baldios, próximos ao rio e no canteiro central da avenida. A situação encontrada é oposta ao levantamento feito por ANDRADE (2002) para a cidade de Campos do Jordão, no qual foi verificado que $41,6 \%$ dos plantios foram realizados em locais sem recuo ou com recuo insuficiente.

A compatibilidade entre o porte da espécie utilizada e o espaço disponível para o plantio foi avaliada, ainda, de forma específica para cada situação. Nesta situação, foi considerada a forma da copa da árvore, a fiação aérea, a largura das calçadas, o afastamento de construções, postes, marquises e de outros vegetais. Verificaram-se 728 indivíduos compatíveis com o espaço disponibilizado para o plantio, 35 indivíduos mediamente compatíveis, já requerendo poda leve para sua adequação, e sete indivíduos 
em situação pouco compatível, requerendo poda pesada para sua adequação ao espaço físico disponível. Em tais situações, o mais adequado seria o plantio de outra espécie de menor porte ou mesmo a não realização de plantio. TEIXEIRA (1999) constatou que 44,9\% dos plantios realizados em Santa Maria, no Conjunto Habitacional Tancredo Neves, estavam compatíveis com o espaço físico disponível. Em ambas as situações, a arborização era recente, com grande parcela composta por indivíduos jovens.

$\mathrm{Na}$ avaliação da distância da árvore ao meio-fio, foi encontrado o valor mínimo de cinco centímetros, médio de 69,8 centímetros e máximo de 2,5 metros. Em muitos casos, porém, não foi feita a medição desta variável em virtude das ruas e passeios não possuírem pavimentação. Santiago (1970) apud Milano (1988) recomenda como ideal uma distância das árvores ao meio-fio entre 30 e $40 \mathrm{~cm}$. Já o PDJ (1979), também citado por Milano (1988), considera que esta não deve ser menor que um metro para se evitar danos físicos às árvores provocados pelos veículos.

\section{Principais problemas verificados na arborização das vias públicas}

Ao percorrer todas as ruas do município realizando o levantamento da arborização, foi possível verificar a ocorrência de algumas situações mais freqüentes de conflito na arborização. Os problemas encontrados não são maiores porque os trabalhos de arborização no município são recentes, com plantios jovens que ainda não estão interferindo com os equipamentos urbanos. Entre eles, merecem destaque:

- Plantio de espécies inadequadas à arborização urbana, em percentual elevado, geralmente exóticas e com características de plantas invasoras.

- Observação de espaçamento inadequado entre as plantas, com o plantio geralmente de mudas muito próximas, inclusive com o plantio de mais de um exemplar na mesma área livre, dificultando a passagem de pedestres e o pleno desenvolvimento das plantas. O espaçamento ideal varia de espécie para espécie e é condicionado pelo diâmetro de copa da árvore adulta. Também foram constatados plantios de árvores próximas a postes de eletrificação e placas de sinalização e em esquinas.

- Plantio de árvores de pequeno porte em espaços que permitiriam o plantio de árvores de porte médio ou grande e vice-versa, com um melhor aproveitamento, desta forma, do espaço disponível e conseqüentemente com ampliação dos benefícios.

- Em inúmeras residências, cujos passeios apresentam potencialidade para plantio, as calçadas estão sendo construídas sem que seja destinada área livre para plantio. É uma situação que precisa sofrer interferência da administração municipal com a definição nos planos urbanísticos da obrigatoriedade de destinar espaços para plantios nos passeios públicos. 
- Ocorrência de árvores danificadas por podas para adequação à rede de fiação elétrica, quebradas pela ação da natureza e por vandalismo e sem qualquer trabalho de manutenção e/ou recuperação.

\section{CONCLUSÕES}

Ao término do estudo da arborização urbana do Município de Sete de Setembro podem-se tecer algumas conclusões e sugestões:

- A arborização do município privilegia espécies exóticas e, apesar da diversidade de espécies encontrada, apenas sete espécies respondem por dois terços da arborização do município, o que não é interessante do ponto de vista técnico e ambiental.

- As espécies Thuja plicata, Bauhinia variegata, Murraya paniculata, Lagerstroemia indica, Ligustrum spp e Cinnamomum sp devem ter seus plantios evitados por serem exóticas e já terem atingido um percentual elevado nos plantios. Além disso, Thuja plicata não é adequada para plantios em passeios públicos, pois não é compatível com podas de adequação, e Murraya paniculata é considerada invasora (INSTITUTO HÓRUS DE DESENVOLVIMENTO E CONSERVAÇÃO AMBIENTAL, 2008). Deve ser privilegiado o plantio de espécies nativas à flora regional.

- A maior parte dos problemas verificados decorre dos plantios voluntários promovidos pelos próprios moradores, nos quais não há observância aos padrões técnicos, o que ocasiona conflitos. A tarefa de arborização deve ser desempenhada pela administração municipal, adotando-se critérios técnicos para seu planejamento e execução. A população deve estar consciente do processo e participar responsabilizando-se pelo cuidado da arborização, pois o sucesso de um projeto de arborização é diretamente proporcional ao comprometimento e à participação da população local.

- É necessária a definição de uma política municipal de arborização urbana, a ser viabilizada através de um plano de arborização urbana que respeite os valores culturais, ambientais e de memória da cidade. Por tratar-se de um município novo, Sete de Setembro tem amplas possibilidades de evitar os problemas que a falta de planejamento já está ocasionando e de usufruir de todos os benefícios de uma adequada arborização.

\section{REFERÊNCIAS}

ANDRADE, T. O. Inventário e análise da arborização viária da Estância Turística de Campos do Jordão, SP. Piracicaba: USP, 2002. Dissertação (Mestrado em Agronomia), Escola Superior de Agricultura Luiz de Queiroz, Universidade de São Paulo, 2002. 
BACKES, P.; IRGANG, B. Árvores do Sul - guia de identificação \& interesse ecológico. [S.I.]: Instituto Souza Cruz, 2002. 326 p.

BACKES, P.; IRGANG, B. Árvores cultivadas no sul do Brasil guia de identificação e interesse paisagístico das principais espécies exóticas. Porto Alegre: Paisagem do Sul, 2004. 204 p.

CONGRESSO BRASILEIRO DE ARBORIZAÇÃO URBANA, 11, 2007, Vitória. Carta de Vitória. Disponível em: <www.sbau.org.br> . Acesso em: 29 mai. 2008.

DETZEL, V. A. A cidade, os espaços abertos e a vegetação. In: CONGRESSO BRASILEIRO SOBRE ARBORIZAÇÃO URBANA, 1; ENCONTRO NACIONAL SOBRE ARBORIZAÇÃO URBANA, 4, 1992, Vitória. Anais. Vitória: Sociedade Brasileira de Arborização Urbana, 1992. p 39-52.

GONÇALVES, W.; PAIVA, H. N. Arborização Urbana. Manual Técnico. Viçosa: CPT, 1997. INSTITUTO BRASILEIRO DE GEOGRAFIA E ESTATÍSTICA. Cidades. Disponível em: <http://www.ibge.com.br/cidadesat/default.php>. Acesso em: 05 nov. 2005.

INSTITUTO BRASILEIRO DE GEOGRAFIA E ESTATÍSTICA. Cidades. Disponível em: <http://www.ibge.com.br/cidadesat/default.php>. Acesso em: 05 nov. 2005.

INSTITUTO HÓRUS DE DESENVOLVIMENTO E CONSERVAÇÃO AMBIENTAL. Base de dados I3N de espécies exóticas invasoras do Brasil. Disponível em: <http://www.institutohorus.org.br/>. Acesso em: 31 mai. 2008.

LONGHI, R. A. Livro das Árvores: árvores e arvoretas do sul. Porto Alegre: L\&PM,1995.

LORENZI, H. Árvores brasileiras: manual de identificação e cultivo de plantas arbóreas nativas do Brasil. 2. ed. Nova Odessa: Instituto Plantarum, 1998.

Árvores brasileiras: manual de identificação e cultivo de plantas arbóreas nativas do Brasil. 3. ed. Nova Odessa: Instituto Plantarum, 2000.

Plantas ornamentais no Brasil: arbustivas, herbáceas e trepadeiras. 3. ed. Nova Odessa: Instituto Plantarum, 2001. 
LORENZI, H. et al. Árvores exóticas no Brasil: madeiras, ornamentais e aromáticas. Nova Odessa: Instituto Plantarum, 2004.

LORENZI, H. et al. Palmeiras brasileiras e exóticas cultivadas. Nova Odessa: Instituto Plantarum, 2004.

LORENZI, H.; MELLO FILHO, L. E. As plantas tropicais de R. Burle Marx. São Paulo: Nobel, 2001.

MILANO, M. S. Avaliação e análise da arborização de ruas de Curitiba - PR. Curitiba: UFPR, 1988. Dissertação (Mestrado em Engenharia Florestal), Setor de Ciências Agrárias, Universidade Federal do Paraná, 1984.

MILANO, M. S. Avaliação quali-quantitativa e manejo da arborização urbana: exemplo de Maringá - PR. Curitiba: UFPR, 1988. Tese (Doutorado em Ciências Florestais), Setor de Ciências Agrárias, Universidade Federal do Paraná, 1988.

MÜLLER, J. Orientação básica para manejo da arborização urbana. Edições FAMURS. Porto Alegre: Nova Prova, 1998.

PREFEITURA MUNICIPAL DE PORTO ALEGRE. SECRETARIA MUNICIPAL DO MEIO AMBIENTE. Plano diretor de arborização de vias públicas e comunidade interativa para Porto Alegre. Porto Alegre: 1996. 34 p.

RIO GRANDE DO SUL. Projeto RS BIODIVERSIDADE. Disponível em:

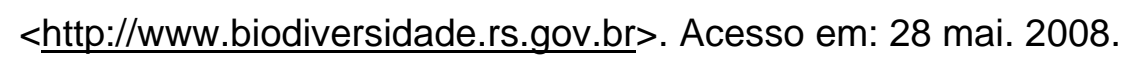

SANTOS, N.R.Z.; TEIXEIRA, I.F. Levantamento quantitativo e qualitativo da arborização do Bairro Centro da cidade de Santa Maria - RS. In: ENCONTRO NACIONAL SOBRE ARBORIZAÇÃO URBANA, 3, 1990, Curitiba. Anais. Curitiba: FUPEF, 1990. p. 263-76.

SANTOS, N. R. Z.; TEIXEIRA, I. F. Arborização de vias públicas: ambiente X vegetação. Santa Cruz do Sul: Instituto Souza Cruz, 2001.

TEIXEIRA, I. F. Análise qualitativa da arborização de ruas do Conjunto Habitacional Tancredo Neves, Santa Maria - RS. Ciência Florestal, Santa Maria, v. 9, n. 2, p. 9-21, 1999. 